\title{
Processos De Subjetivação De Professor-Andarilho-Cartógrafo
}

\author{
Procesos De Subjetivación De Profesor-Andarilho-Cartógrafo \\ Teacher-Walker-Map Maker Subjectivation Processes
}

\author{
Ronaldo Luis Goulart Campello ${ }^{1}$ \\ Ursula Rosa da Silva ${ }^{2}$
}

\begin{abstract}
Resumo
Este texto surge a partir de uma atividade docente que se tornou projeto de extensão/pesquisa e que resultou na dissertação de mestrado realizada no Instituto Federal de Educação, Ciência e Tecnologia Sul-rio-grandense IFSUL - campus Pelotas, hoje esta proposta de pesquisa é pensada no programa de pós-graduação - Mestrado em Artes Visuais da Universidade Federal de Pelotas - UFPEL, busca articular uma escrita cartográfica, que pensa os processos de formação de um professor-pesquisador-poeta-andarilho que tem no uso das palavras instrumentos para vir a ser... Esta em devir, e debruça sobre uma prática de escrita muito antiga, cartas epistolares. O exercício manuscrito desta forma textual surge como uma prática de ensino, com a intenção de amenizar as dificuldades de aprendizagem com a leitura e a escrita, e à medida que esta pesquisa se produzia passamos a tratar tal exercício como processo de formação mais amplo, compreendendo a escrita como uma prática capaz de reinvenção de modos de pensar e ser. Errar a palavra e torná-la outra, é um cuidado. Autores como Deleuze e Guattari, Foucault e Larrosa, dão suporte ao campo problemático desta pesquisa que se faz em meio ao método cartográfico, onde ler, escrever, experimentar são vistos como processos de formação e criação.
\end{abstract}

Palavras-Chave: Escrita; Formação; Cartas epistolares; Experiência; Cartografia.

\section{Resumen}

Este texto surge a partir de una actividad docente que se convirtió en proyecto de extensión / investigación y que resultó en la disertación de maestría realizada en el Instituto Federal de Educación, Ciencia y Tecnología Sul-riograndense - IFSUL - campus Pelotas, hoy esta propuesta de investigación se piensa en el programa de postgrado - Maestría - en Artes Visuales de la Universidad Federal de Pelotas - UFPEL, busca articular una escritura cartográfica, que piensa los procesos de formación de un profesor-investigador-poeta-caminante que tiene en el uso de las palabras instrumentos para venir a ser ... Esta en devenir, y inclina sobre una práctica de escritura muy antigua, cartas epistolares. El ejercicio manuscrito de esta forma textual surge como una práctica de enseñanza, con la intención de amenizar las dificultades de aprendizaje con la lectura y la escritura, ya medida que esta investigación se producía pasamos a tratar tal ejercicio como proceso de formación más amplio, la escritura como una práctica capaz de reinvención de modos de pensar y ser. Errar la palabra y hacerla otra, es un cuidado. Los autores como Deleuze y Guattari, Foucault y Larrosa, dan soporte al campo problemático de esta investigación que se hace en medio del método cartográfico, donde leer, escribir, experimentar son vistos como procesos de formación y creación.

Palabras claves: Escrita; Formación; Cartas epistolares; La experiencia; Cartografía.

\begin{abstract}
This text emerges from a teaching activity that became an extension / research project and resulted in a master's dissertation held at the Federal Institute of Education, Science and Technology Sul-rio-grandense - IFSUL -

${ }^{1}$ Mestre em Educação em linguagens verbo visuais e suas tecnologias, IFSul; Pelotas; Rio Grande do Sul; Brasil; ronaldo.luiscampello@gmail.com

${ }^{2}$ Doutora em Educação, Universidade Federal de Pelotas (UFPEL); Pelotas; Rio Grande do Sul; Brasil; ursularsilva@gmail.com
\end{abstract}


Campotas Pelotas, today this research proposal is thought in the post-graduate program - Master's Degree - in Visual Arts of the Federal University of Pelotas - UFPEL, seeks to articulate a cartographic writing, which thinks the processes of formation of a professor-researcher-poet-walker who has in the use of the words instruments to come to be ... It is in turn, and looks over a practice of very ancient writing, epistolary letters. The manuscript exercise of this textual form appears as a teaching practice, with the intention of softening the difficulties of learning with reading and writing, and as this research was carried out, we began to treat such exercise as a process of broader formation, including writing as a practice capable of reinventing ways of thinking and being. To err the word and make it another, is a care. Authors like Deleuze and Guattari, Foucault and Larrosa, support the problematic field of this research that is done in the middle of the cartographic method, where reading, writing, experimenting are seen as processes of formation and creation.

Keywords: Writing; Formation; Letter letters; Experience; Cartography.

\section{Introdução}

Este texto tem como intuito tratar de uma proposta de pesquisa que surge a partir de um palimpsesto, pois se experimenta seguir pensando e articulando ideias de escritos que ficaram de outra pesquisa de mestrado realizada (2015/17) anteriormente, posto que, uma escrita não se concluiu, ela deixa rastros/pistas, pegadas a serem seguidas por si próprio ou outros. E, é neste viés de pensamento que se busca seguir perseguindo o vento, as palavras que dêem conta de expressar os processos de subjetivação de um professor-pesquisadorpoeta-andarilho...

Escrever possui afinidade, parentesco, uma semelhança, um avizinhar-se com movimentos, escrever é mover-se. É como areia no deserto. Esta pesquisa se faz no Programa de Pós-Graduação - Mestrado - em Artes Visuais da UFPEL, tendo como proposta uma escrita cartográfica, que pensa os processos de formação que tem no uso das palavras instrumentos para vir a ser... Estar em devir.

Este texto, este tecido-texto é um experimento que surge de um palimpsesto, e, é importante que você saiba, pois $\mathrm{n}[\mathrm{d}] \mathrm{ele}$ busco uma escrita antes. Uma escrita da qual trago linhas que escapam e vou tricotando, tramando, tecendo assim como tece a aranha teias, fios, das quais faz sua morada. Aqui vou tentando tessituras novas a partir de uma escrita que escapou de outra pesquisa que parte de uma atividade docente que se tornou projeto de extensão/pesquisa e que resultou em uma dissertação, uma proposta de prática menor que se debruça sobre um método de escrita muito antiga, cartas epistolares.

O que busco ao experimentar este novo-antigo texto que hoje [2018] é pensado no programa de pós-graduação do Mestrado em Artes Visuais da Universidade Federal de Pelotas - UFPEL é necessidade de pensar a escrita como um exercício de escuta, de resistência. De formação. Errar a palavra e torná-la outra. Um cuidado, ou talvez pensar o que pode escapar do silêncio? Escrever é um cuidado, de si de outros... 
Penso sobre formação quando escrevo sobre tal processo, sobre os encontros e os atravessamentos produzidos em mim. Escrever é estar em outros lugares, é mover-se em meio à... É experimentar, e o que busco neste novo-antigo texto é dar margem a uma escrita estética que de conta de suportar alguns conceitos que preciso para pensar antes de tudo, meu professorado.

Ao experimentar este tecido-texto que busca operar um método, articulando uma escrita cartográfica, que pensa os processos de formação de um professor-pesquisador-poetaandarilho que têm no uso deste fazer, a escrita, instrumentos para vir a ser... estar em devir, e que busca escapar pelas frestas das palavras, resistir nas fissuras que provoca em sua docência e que anda as margens de um caminho que faz só, em solidão, mas que por vezes traz companhias e busca, deste modo uma estética nova a uma escrita sua já gasta, quiçá oca, mas que ainda lhe inquieta, e questiona ao criar a palavra: $\mathrm{O}$ que precisa para sair do silêncio? Quais lugares novos ou antigos ocupa? Ou onde se encontra o ruído de sua escrita? Quais lugares que já tenha caminhado, já tenha estado - de vazio; de névoas; de sublime - antes são potentes para pensar sua do[c]ênc[i]a...?

Antecipo-lhe que não tenho ainda uma pergunta para responder, não há nenhuma questão, ainda tão potente, que possa dizer que seja a que me move a problematizar este trabalho, são várias 'inquietações', e, talvez algumas sejam, mas outras provavelmente não, perguntas norteadoras as quais vou usando para mover-me em meio a este texto. Isso é resultado dos atravessamos que irão perquirir esta escrita. Existirão perguntas sem respostas, muitas as quais sigo perseguindo tal como poeira perseguindo o vento, pois ando neste momento por caminhos que não são mais os mesmos, por desertos onde as estrelas são outras, pois mesmo que se volte por um mesmo caminho inúmeras vezes ele sempre será novo, pois sempre existirão novos cheiros, novas paisagens, novas texturas que deixamos escapar, um novo paladar, pois sempre existirão novas perguntas sobre um mesmo tema, que como fratura, irá estar sempre lá nos lembrando da queda. Há sempre uma nova pergunta a ser feita, pois uma ou algo escapou... Ficou no entre.

\section{Tecendo textos, tramando ideias}

Escrever acontece a partir do encontro de energias que se tece com a leitura, com os corpos, com atravessamentos, encontros com nós mesmos, com os outros. Escrever parece simples, mas, não é. É um esforço colossal.

Escrever é trair, trair é difícil porque é criar; toda criação implica traição, desvio, fuga: criar é deixar-se levar pela intensidade e instantaneidade de fluxos que se 
desterritorializam conjugando-se a outros fluxos, que por sua vez o desterritorializam e vice-versa: assim é o escrever, a escritura opera por conjugação e transmutação de fluxos, produzindo novos devires. Escrever é um ato potencializador de formas de resistência/transformação que se materializam no exercício de uma epistemologia conectiva, que dá ao pensamento uma outra direção. [PÉREZ, 2003, p. 181]

Escrever surge de agenciamentos, desejos de tecer textos, teias, tecidos, tramar, trair, transformar pensamento em ideia, dar corpo ao que é incorpóreo, corporificar o que faz furos na pele, desenhar, mostrar, dar a ver o que cartografarmos, rizomaticamente nas regiões ainda por vir. É energizar a criatividade. Escrever é encontro: interno e intenso é devir, sempre por se fazer [DELEUZE, 1992]. Escrever é desconstrução que ocorre de maneira singular, construção que se faz de forma sutil, nos reconstruindo com mais experiências, é movimento que revela pistas, deixa rastros/pegadas pelos quais se esgueiram desejos. Escrever é criar, ligar pontos, pontas, pedaços, platôs por onde flanamos a espreita resistindo aos modelos padronizantes tradicionais. O pensar é questão intrínseca/encrunhada no ato de promover as primeiras linhas ao se produzir uma escrita. "Pensar [...] é um ato perigoso [...] é sempre seguir a linha de fuga do voo da bruxa" [DELEUZE \& GUATTARI, 1992, p. 58-59], por isso é tão difícil escrever. Pouco se exercita o pensamento, pois não nos colocamos sentados em vassouras e singramos os céus, pouco nos movimentamos-pensamos-permitimos nos colocar em devir.

Pensar é dar carne ao verbo, criar voz na palavra úmida, deixar prenhe os pulmões, de algo que quer sair, algo que pede passagem, que esta lá na quietude. Pensar envolve agenciar dispositivos que criam corpo. Modificam o que antes era silêncio e agora é palavra. E, agora palavra, toma vida e funciona a partir de dispositivos criados/pensados desde o agenciamento, desde o desejo. Desde o que antes não existia estava em segredo instaurado no caos de das lembranças.

É na solidão de minha consciência que busco compor/agenciar este caos, pois escrever para mim é uma provocação, uma afronta que gera encontros, "minha escrita brota da solidão, do fundo desta solidão encontro pessoas, ideias e pensamentos. Minha solidão está povoada de vozes, de textos, de palavras, de encontros, histórias, acontecimentos e imagens". [PÉREZ, 2003, p. 01]. Busco esta solidão, para encontrar-me com outros que me habitam, transitam, agenciam-se em mim e por entre mim; não no sangue de minhas veias, no suor de minha pele, nas rugas de minhas faces, mas nas formas mais sensíveis de sentir como sinto a brisa que me 
toca. Busco a solidão, pois ela "só é boa quando voluntária"3, é nela que tais encontros, agenciam (os) outros que se mostram na palavra-verbo-texto-escrita.

É no encontro do rio com a roda d'água, com suas aletas de madeira, que faz a mó girar e o moinho produzir, transformar o grão em farinha, é no encontro da escrita com a expressão, que a palavra se faz. No desejo que existe de saciar vontades. Desejar é agenciar, é tecer rizomas, produzir encontros como o que acontece como o tosquiar a ovelha o mais rente à pele, para aproveitar-se da fibra em seu maior comprimento, e retirar o velo com cuidado, lavar, esgadelhar, cardar e fiar o fio, torcê-lo, ensarilhar, dobar e após, com ele tecer, tricotar, cerzir, atar, amarrar, ligar pontos, pontas, peças, criar. Agenciar é trazer corpos biológicos ou não, mesmo que de outros planos, que não sejam comuns. Do tosquiar a ovelha se produz o fio de lã, do fio se produz peças, e isso a partir do desejo de querer uma peça - seja ela qual for, mas é preciso outros elementos, a ovelha, o tosquiador, a artesã, a roca o fiar o fio e todo o processo que isso envolve. Nunca se deseja algo só, mas em conjunto [DELEUZE 1992], a abelha e a orquídea, o rio e o moinho, o corvo e a presa, criam-se territórios a partir do agenciamento de desejos que se constroem, desconstroem e se reconstroem em planos de imanência.

De nada serve escrever se esta escrita não fortalece não desconstrói para uma nova construção, de nada serve se ela não desterritorializa. "Pensar é desterritorializar. Isto quer dizer que o pensamento só é possível na criação e para se criar algo novo, é necessário romper com o território existente, criando outro" [HAESBAERT et al, 2015, p. 09]. Há de existir uma identidade que se desconstrua, que não seja fixa, que se afete por aquilo que nos passe, por aquilo que a escrita de si proporcione.

A desterritorialização a partir do pensamento cartográfico consiste segundo Ianni em "[...] o sujeito do conhecimento não permanecer no mesmo lugar, deixando que seu olhar flutue por muitos lugares, próximos e remotos, presentes e pretéritos, reais e imaginários" [1996, p. 16]. Ao escrevermos lemos e ao lermos nos constituirmos aos poucos. Desta forma, observarmos o que se passa; o que nos passa, "los gestos donde asumimos y soportamos lo que nos pasa - el acontecimiento - y es en ellos donde acontece una experiencia no meramente prescritiva o normativa de la formación” [BÁRCENA 2012, p. 67]. Escrevemoslemos-escrevemos num exercício, como forma de atividade. E quando o fazemos, estamos em outro território, um território fértil transformador, a partir de acontecimentos, de encontros

\footnotetext{
${ }^{3}$ Trecho da música 'solidão' da banda pelotense de dark metal m26 que compõe o CD Misantropia 2015. Independente.
} 
que nos exigem formas de expressão. $\mathrm{O}$ encontro em Deleuze dispara uma força criativa.

A escrita surge, aqui, como instrumento de formação, "não é aprender algo, a questão não é que, a principio, não sabíamos algo e, no final, já o sabíamos”, [LARROSA, 2015, p. 52], mas sim, a formação de algo que incorpora um aprendizado. É o novo que se apresenta e é posto nas linhas abissais do papel, buscando pensar a escrita como um meio/forma de expressão libertadora que nos possibilita romper linhas impostas. "A escrita transforma a coisa vista ou ouvida" [FOUCAULT, 1992, p. 134], dá sentidos ao que queremos nominar, e, a este nominar, temos a oportunidade de produzir um exercício de auto experimentação.

É necessário ter um novo observar, um olhar de forasteiro sobre o objeto observado, mesmo que isso não seja fácil de produzir, é preciso tomar distância, flanar como o andarilho que se perde em meio às multidões, pelos caminhos que a cidade lhe oferece, absorto em seus pensamentos, observando todo detalhe possível que pode o flâneur observar.

Ao usar a palavra para escapar de meu silêncio sinto-me frágil. A deriva. Só em meio a ecos de vozes opacas onde ouso arriscar e resistir por entre as beiradas de linhas [de fuga] que se fazem sempre presentes para tentar expressar o que penso querer expressar.

Ouso sair pela dobra, pela fresta, por aquela linha que rasuro, ou que tento criar, no barro do qual dou forma ao verbo que componho. Ouso escapar pelas reticências que uso. No hiato que há entre uma e outra. Demasiadas. Potentes. Reticências das quais me aproprio e crio com elas espaços que são por vezes mais frágeis que a tempestade que se esvai em meio ao silêncio...

E, é deste silêncio que procuro buscar artifícios para silenciar as vozes que ouço que sozinho. Outros de mim dos ouso escapar pela poesia que me toma. Poesia esta que é em mim desterritorialização, e que deixa rastros os quais persigo... Rastros que levam-me a usar uma língua que é afiada, cortante, simbólica. Que me faz andar descalço. Tocar com os pés nus o solo árido deste deserto que é prece, que faz palavras, que faz chagas na planta já em prantos do que ainda toca o solo. É esta palavra que me trás de volta e que toma de mim emprestado o que me faz tomar distância deste silêncio. A palavra...

Uso a palavra como uso o corpo para caminhar. Escrever é um modo de por em movimento pensamento. Caminhar é resistência. O silêncio também. Escrever é uma ação perigosa. Descrever é tornar ação. Ato. É estar em outros lugares que o corpo não esta e por isso precisa caminhar, mover, mover-se em meio a... dentro de... espaços que podemos criar ou já são criados por nós ou outros, ou outros de nós. Ao caminhar pensando em criar a palavra que preciso para sair do silêncio, ocupo lugares novos, mesmo que por eles já tenha caminhado, já tenha [um] estado [de vazio; de névoas; de sublime] - antes... Errar a palavra e 
torná-la outra. É buscar na escrita encontrar processos de subjetivação que encarnem [um outro] o professor-pesquisador-poeta-andarilho um cartógrafo.

\subsection{Apresentando o método}

Alguém um dia disse que a escrita é uma fala de si. Um abrir-se. Que é fácil falar/escrever de coisas de seu dia a dia, e isso se intensifica na escrita de cartas pessoais; por exemplo. Falar sobre o que me inquieta, me perturba como docente, questionar meu exercício profissional já é algo grande demais. “As cartas que escrevo. Correspondências físicas na era digital uma metodologia interdisciplinar de ensino e aprendizagem", iniciado no ano de 2014, ganha força em 2015, e se constitui em pesquisa, toma outro nome, enquanto é realizada no Mestrado Profissional em Educação e Tecnologia - MPET, do Instituto Federal de Educação, Ciência e Tecnologia Sul-rio-grandense - IFSUL campus Pelotas - RS, Brasil; "Cartas para ler e escrever: Cartografando uma prática de ensino", ganha vida a partir do referido projeto de extensão, e a partir de minha docência em uma escola técnica estadual no bairro Fragata na mesma cidade. Tal pesquisa buscou a partir de meu objeto de pesquisa, cartas pessoais; cartografar encontros, acontecimentos, a partir de práticas de escrita e leitura de um grupo de estudantes de um quinto ano do ensino fundamental desta escola técnica estadual, onde este grupo se correspondeu com outros, também estudantes de um quinto ano de uma escola rural no interior do município de Piratini - RS, tal movimento se constituiu ao longo de um ano especifico, 2015. “A correspondência é também um exercício pessoal, ao escrever lemos o que escrevemos, [...] é uma maneira de se manifestar para si e para o outro", [ORRÚ \& ANDRADE, 2009, p. 04].

Em 2014, tinha como proposta inicial amenizar as dificuldades de escrita e leitura dos estudantes que chegam ao quinto desta referida escola, em 2015 se vai além, e, portanto, na pesquisa se cartografa os encontros destes grupos distintos de alunos.

Ao ingressar no Programa de Pós-Graduação (Mestrado) em Artes Visuais da UFPEL o ato de escrita me põe em movimentos de ida e volta, tanto em sua escrita quanto leitura, aqui faço cartografia, pois vou me construindo, desconstruindo e reconstruindo, sempre em outro lugar no processo de composição desta nova-antiga pesquisa que deixa fraturas expostas, deixa perguntas sem respostas das quais as sigo perseguindo tal como poeira perseguindo o vento. Ando por caminhos que não são mais os mesmos, pois mesmo que se volte por um mesmo caminho inúmeras vezes ele sempre será novo, pois sempre existirão 
novos cheiros, novas paisagens que deixamos escapar, sempre existiram novas texturas, pois uma escapou...

Portanto, tratar de problematizar o ato de escrever novamente é cartografar, pois escrever me afeta, se me afeta faço cartografia, problematizo minha docência antes de tudo, ela é como os poemas que componho que nunca estão acabados, são rascunhos, de rascunhos de algo que esta por vir, algo que esta para chegar e não chega, são as reticências que uso, sempre a espreita, sou um andarilho "formado nas problematizações do mundo, nos desvios, nos lapsos, ali onde algo escapa ou onde não encontramos o que ansiamos encontrar" [POZZANA, 2014, p. 61]. Ao buscar respostas para tentar amenizar as dificuldades deste grupo de alunos, percebo que minha docência se afeta, portanto, ademais, penso sobre formação quando me ponho a escrever sobre tal processo e os atravessamentos que foram produzidos em mim a partir da execução desta prática que tomo como ensino, escrita de cartas. Uma resistência, uma prática menor de ensino. Uma prática de ensino como sugestão de educação-menor ${ }^{4}$ que trago à minha sala de aula em um projeto de ensino, um dispositivo, que tem como proposta de atividade: os estudantes escreverem sobre si, uma forma de escrita menor, transgressiva, a partir de a escrita epistolar. A literatura menor é um conceito estético criado por Deleuze e Guattari, onde: “o 'menor' já não qualifica certas literaturas, mas as condições revolucionárias de qualquer literatura no seio daquela a que se chama grande - ou estabelecida" [DELEUZE; GUATTARI, 2014, p. 39].

No decorrer desta escrita às ideias vão surgindo e algumas são acrescidas, outras descartadas. A leitura de outros textos e o flanar por entre outras vias produzem encontros. Alguns excertos na cartografia brotam/surgem como um estilo na configuração do trajeto da pesquisa e implicam profundamente as ações no ato de produzir, de entender os alinhavos das redes, das teias, do rizoma. É importante dizer que um "rizoma não começa nem conclui, ele se encontra sempre no meio, entre as coisas" [DELEUZE e GUATTARI, 1995, p. 04], nas oscilações da construção do campo conceitual, por exemplo, dos mapas e dos platôs por onde o pensamento se faz. No projeto com as cartas, a escrita das mesmas provocava a leitura de outros textos, a leitura de outras missivas, promovia o aprendizado de outros conteúdos que remetiam a encontros com outros temas, e até mesmo um novo olhar sobre o que já se sabia.

Na cartografia da ciência geográfica aprendemos inúmeras definições sobre escala, topografia, paisagens, localização, hidrografia etc. para unir tais elementos em um croqui,

\footnotetext{
${ }^{4}$ Conceito que Sílvio Gallo 'desloca' da obra de Deleuze \& Guattari, Kafka - por uma literatura menor, para operar como dispositivo para pensarmos a educação, sobretudo aquela que praticamos no Brasil em nossos dias. Sílvio Gallo (2002, p.169).
} 
uma carta topográfica ou um mapa para interpretar/ler tal documento. Na cartografia proposta por Deleuze e Guattari [1995], o procedimento cartográfico assume outra política. Experiências, acontecimentos e conceitos se aliam e mergulhamos em outros campos. Tratase de uma geografia dos afetos, das sensibilidades, dos movimentos e das subjetividades que podem, assim, pensar sobre procedimentos de transformação que afetem/possibilitem implicações no individual e também no coletivo. Pesquisador e problema de pesquisa. Pesquisador do problema de pesquisa.

\subsection{Escapar...}

Tencionar sobre o que me inquieta e me perturba como docente, e faz-me questionar meu exercício profissional pondo em xeque o que penso estar fazendo como correto já é algo grande demais, acompanhar este processo é algo admirável, pois não é fácil olhar dentro de si, perceber que parte das peças de engrenagem que o fazem funcionar não está mais servindo. Desarraigar-se de conceitos já enraizados, olhar o abismo, e deixar que ele olhe você. "entender do que pode ser feita uma possível estética de si docente: um diferir-se permanentemente do que se é, um modo artista de constituir-se [LOPONTE, 2010, p. 22]. Percorrer os rastros que me trouxeram aqui já é uma longa história a se falar, é transitar nos sulcos de minhas faces, nas linhas que se traçaram ao longo dos anos, é cartografar, ou seja, seguir seus rastros, seus movimentos, amplitudes e alterações, seus movimentos que mostram os encontros que ocorreram e me puseram a pensar, um movimentar-se, a partir do cotidiano e seus modos de se produzir no/com/ele. "E se nos pusermos a pensar em educar como um cão que cava seu buraco, um rato que faz sua toca? No deserto de nossas escolas, na solidão sem fim, mas super povoada - de nossas salas de aula não seremos, cada um de nós, cães e ratos cavando nossos buracos?'[GALLO, 2002, p.169] produzindo aqui, e desta uma forma, um modo de militância, de resistência ao modo comum de lecionar, cavando tocas e mais tocas e esgueirando-se por elas buscando um modo de pensar educação.

Ao compor minha fala através de palavras escritas cristalizo o que me faz pensar quem sou sob as máscaras que o tempo produziu. Debruçar-se sobre si mesmo, é escavar as capas que lhe constituem, retirar uma a uma as camuflagens imprescindíveis ao convívio em sociedade, à falsidade dos meios sociais nos quais nos colocamos, compõem um processo tão difícil quanto mover uma montanha.

Escrever é um verbo que se imprime só, mas que reverbera a multidões. Não importa a quais multidões, mas lenta e vagarosamente a escrita, o texto, atinge seu fim, seu destino. Não 
um fim de chegada, de término, mas um fim no sentido de esbarrar-se com algo/alguém. Ele cumpre seu papel de instigar uns, mover outros, de amparar outros tantos, assim como também não toca, não faz sentido, não se faz legível.

É dos lapsos cruéis de realidade que busco escapar, e na procela herética da palavrapoesia cavalgar tropéis pueris de palavras-cambaleantes tendo abaixo dos véus de meus olhos poeira e vento que transcendem em uma artesania, de fazer-ser, aguçar, sentir e buscar alcançar no febril verbo notas dissonantes que escapam em um vir a ser...

Desterritorializando processos micropolíticos impulsionando um corpo que oscila em uma palavra-poesia, um professorado e um estado de arte. Um cuidado de si talvez? Um fazer-ser professor-pesquisador-poeta-andarilho, que anda as margens de uma educação maior, com sinais possíveis de uma prática menor, catando tudo que serve, ou pode servir para descolonizar um pensamento-escravo, submisso a ditos e não ditos, que se escondem nas capilaridades do aprender. O aprender é uma arte "que consiste em um processo a ser incessantemente recomeçado" (DELEUZE, 2005, p. 1184).

Por onde caminhar em meio ao caos que agora desenho com o sangue que inunda as palmas de minhas mãos? Por onde esgueirar-me se no silêncio que ocupo os ruídos de minha escrita escapam, pois, precisaras saber que apaguei todas as trilhas que havia construído com os signos de minha escuta e verbo que me habitam e criam palavra...

Deles o que me habita são poucos sonhos... Até mesmo as pegadas não as tenho mais... O deserto fechou suas portas e dele não colho mais seus aromas, somente o sol me brinda as faces impondo-me que ande com os ombros curvados procurando alguma trilha, uma fugidia visão, uma febre...

Não busco na homeopatia das ervas a cura, mas em seus vapores deixar este plano, tomar distância e observar, como o pássaro que do alto me reprimi, o platô por onde me perco.

\section{Conclusões}

Ao escrever este texto, ao fazer esta nova caminhada por um caminho já percorrido, ao ir apagando e reescrevendo esta escrita, fui lentamente desvelando numerosos temas, ocultando outros, não percebendo que alguns fugiram, e ao passo que ia caminhando, um pouco por vez, e mesmo quando parava às margens do caminho [no entre] e analisava, e por vezes conseguia me elevar, e do alto observara que nesta caminhada houve resistências, aproximações de movimentos distintos, de um olhar sensível. Movimentos que se fazem $\mathrm{d}[\mathrm{n}]$ os lapsos. Uma educação feita de escolhas. Um cuidado de si talvez? 


\section{Referências}

BÁRCENA, F. El aprendiz Eterno. Filosofía, educación y el arte de vivir. Miño y Dávila Editores, Madrid. 2012. (Obra completa)

DELEUZE, G. GUATTARI, F. Kafka: por uma literatura menor / Gilles Deleuze, Félix Guattari; tradução Cíntia Vieira da Silva; revisão da tradução Luiz B. L. Orlandi. -1. Ed.; 1. reimp. - Belo Horizonte: Autêntica Editora, 2014. (Filô/Margens, 4) (Obra completa)

DELEUZE, G. GUATTARI, F. O que é a filosofia? Rio de janeiro: Ed. 34, 1992. (Obra completa)

DELEUZE, G.; GUATTARI, F. Mil Platôs: Capitalismo e Esquizofrenia, v.1. Rio de Janeiro: Editora 34, 1995. (Obra completa)

FOUCAULT, M. A escrita de si. In: .O que é um autor? Trad. António Fernando Cascais e Edmundo Cordeiro. Lisboa: Editora Vega. 1992. p. 129-160. Disponível em: < file:///D:/Users/Ronaldo/Downloads/Foucault\%20Michel\%20A\%20escrita\%20de\%20si\%20( 1).pdf> acessado em 26/03/16. (Artigo em Periódico Digital)

GALLO, S. Em torno de uma educação menor. Educação e realidade. 27(2): 169-178. jul./dez. 2002. Disponível em: http://seer.ufrgs.br/educacaoerealidade/article/download/25926/15194> acessado em 09/08/16. (Artigo em Periódico Digital)

HAESBAERT, R. BRUCE, G. A desterritorialização na obra de Deleuze e Guattari. Disponível em: <http://webcache.googleusercontent.com/search?q=cache:ApuUgDg4s4J:www.uff.br/geograp hia/ojs/index.php/geographia/article/viewFile/74/72+\&cd=1\&hl=ptBR\&ct=clnk\&gl=br $>$ acessado em 10/06/15. (Artigo em Periódico Digital)

IANNI, O. Teorias da globalização - $3^{\mathrm{a}}$ edição - Editora Civilização Brasileira. Disponível em:

<http://webcache.googleusercontent.com/search?q=cache:0Qv4XjSCIhMJ:ucbweb.castelobra nco.br/webcaf/arquivos/12896/7869/DESTERRITORIALIZACAO__Onipresenca_na_Ciran da_Global.doc $+\& \mathrm{~cd}=2 \& \mathrm{hl}=\mathrm{pt}-\mathrm{BR} \& \mathrm{ct}=\mathrm{clnk} \& \mathrm{gl}=\mathrm{br}>$ acessado em 30/08/2015. (Artigo em Periódico Digital)

LARROSA, J. Pedagogia profana: danças, piruetas e mascaradas/ texto de Jorge Larrosa, tradução de Alfredo Veiga-Neto, - 5, Ed.; 2. reimp. - Belo Horizonte; Autentica Editora, 2015. (Obra completa) 
LOPONTE, G. L. Nós, metamorfoses estéticas e educação. In Ensino de arte e (des)territórios pedagógicos. Mirela Ribeiro Meira / Ursula Rosa da Silva [org] IAD/Projeto Arte na Escola. - Pelotas: Editora e Gráfica Universitária, 2010. (Capítulo de Livro)

ORRÚ, C. M. S. F. ANDRADE, M. B. P. $15^{\circ}$ Seminário de Pesquisas em Linguística Aplicada. A escrita de si e o caráter revelador da escrita em textos não verbais. 2009. (Seminário). Disponível

em: $<$ http://site.unitau.br/scripts/prppg/la/5sepla/site/comunicacoes_orais/artigocarla_maria_marie ta_benedita.pdf> acessado em 22/09/15. (Artigo em Periódico Digital)

PÉREZ, C. L. V. Imagens caleidoscópicas: as narrativas autobiográficas na formação das professoras alfabetizadoras. In: $21^{\circ}$ Seminário Internacional: As redes de conhecimento e a tecnologia: imagens e cidadania, Rio de janeiro, 2003. Disponível em:< https://books.google.com.br/books?id=43eGpSi70RgC\&pg=PA178\&lpg=PA178\&dq=Minha +escrita+brota+da+solid\%C3\%A3o,+do+fundo+desta+solid\%C3\%A3o\&source=bl\&ots=Fo moOR94Hy\&sig=KpRrEAuXmFAqQ1KYSXbeKNFrsY4\&hl=ptR\&sa=X\&ved=0ahUKEwiI 6wr73OAhUDhpAKHYTcBfgQ6AEIHjAA\#v=onepage \&q=Minha\%20escrita\%20brota\%20d a\%20solid\%C3\%A3o\%2C\%20do\%20fundo\%20desta\%20solid\%C3\%A3o\&f=false >acessado em 12/08/16. (Artigo em Periódico Digital)

POZZANA, L. A formação do cartógrafo é o mundo: Corporificação e afetabilidade. In Pistas do método da cartografia: a experiência da pesquisa e o plano comum / organizado por Eduardo Passos, Virginia Kastrup e Silvia Tedesco - Porto Alegre: Sulina, 2014. 310 p. (2). (Capítulo de Livro)

ROLNIK, Suely: Cartografia Sentimental, Transformações contemporâneas do desejo, Editora Estação Liberdade, São Paulo, 1989. (Obra completa) 